\title{
Morfogênese de braquiárias sob estresse hídrico
}

[Morphogenesis of Brachiarias species under water stress]

\author{
C.F.D. Duarte, D.L. Prochera, L.M. Paiva, H.J. Fernandes, T.T. Biserra, \\ L.H. Cassaro, L.S. Flores, R.L. Fernandes
}

Universidade Estadual de Mato Grosso do Sul - Aquidauana, MS

\begin{abstract}
RESUMO
Objetivou-se avaliar Urochloa spp. submetida a duas situações de estresse hídrico: déficit e alagamento. As forrageiras estudadas foram: U. humidicola cv. Tully, U. humidicola cv. Llanero, U. brizantha cv. BRS Piatã, $U$. brizantha cv. Xaraés, $U$. decumbens cv. Basilisk e $U$. ruziziensis cv. Kenedy, e os parâmetros avaliados foram relacionados às características estruturais e morfogênicas. $\mathrm{O}$ trabalho foi desenvolvido em casa de vegetação pertencente à Unidade Universitária de Aquidauana. Os tratamentos consistiram em diferentes condições de umidade do solo: 50 e $80 \%$ da capacidade de retenção de umidade do solo, e lâminas de $0 \mathrm{~cm}, 1 \mathrm{~cm}$ e $5 \mathrm{~cm}$ de água acima do solo, com quatro repetições, em delineamento inteiramente ao acaso. O modelo considerou o efeito de umidade do solo para cada espécie forrageira a $5 \%$ de significância. As características estruturais e morfogênicas do capim-tully não foram afetadas pelas diferentes condições hídricas aqui avaliadas. O capim-llanero não reagiu ao alagamento. O capim-piatã foi tolerante às condições de déficit hídrico e apresentou mecanismos de adaptação ao alagamento. A $U$. decumbens $\mathrm{cv}$. Basilisk apresentou respostas adaptativas que melhoram sua tolerância ao alagamento. A U. ruziziensis $\mathrm{cv}$. Kenedy apresentou-se inapta às condições de alagamento e de déficit hídrico.
\end{abstract}

Palavras-chave: alagamento do solo, déficit hídrico, encharcamento do solo

\begin{abstract}
The aim of this study was to evaluate braquiarias submitted to two situations of water stress: deficit and flood. The studied forages were: $\mathrm{U}$. humidicola $c v$. Tully, U. humidicola $c v$. Llanero, U. brizantha $c v$. BRS Piatã, U. brizantha $c v$. Xaraés, U. decumbens $c v$. Basilisk and U. ruziziensis $c v$. Kenedy, and the parameters evaluated were related to the structural and morphogenic characteristics. The work was carried out in a greenhouse at the University Unit of Aquidauana. The treatments consisted of different soil moisture conditions: 50 and 80\% of the moisture retention capacity of the soil, and slides of $0 \mathrm{~cm}$, $1 \mathrm{~cm}$ and $5 \mathrm{~cm}$ of water above the soil, with four replications, in a completely randomized design. The model considered the effect of soil moisture for each forage species at 5\% of significance. The structural and morphogenic characteristics of grass-tully were not affected by the different water conditions evaluated here. The grass-llanero did not react to flooding. The grass-piatã was tolerant to water deficit conditions and presented adaptation to flooding. The $\mathrm{U}$. decumbens $c v$. Basilisk presented adaptive responses that improved its tolerance to flooding. The U. ruziziensis $c v$. Kenedy was unfit for flood and water deficit conditions.
\end{abstract}

Keywords: soil flooding, water deficit, soil drenching

\section{INTRODUÇÃO}

Os capins do gênero Urochloa são os mais cultivados no Brasil, devido à diversidade de espécies e suas diferenças morfofisiológicas.

Recebido em 16 de junho de 2018

Aceito em 17 de janeiro de 2019

E-mail: camilafernandesd@hotmail.com
Espécies desse gênero apresentam boa adaptação, podendo ser cultivadas em várzeas inundáveis, margens de florestas ralas e até regiões semidesérticas. Esse gênero também é caracterizado pela adaptabilidade a solos de média a baixa fertilidade e mal drenados (Valle et al., 2004). 
Valle et al. (2001) atribuíram a esse gênero a expressividade da pecuária brasileira conquistada a partir da década de 60. Os autores afirmaram ainda que a substituição das pastagens nativas por gramíneas de Urochloa foi favorável devido às características oportunas, tais como propagação por sementes, possibilidade de consórcio com outras culturas anuais, facilidade de manejo e persistência em solos de baixa fertilidade. Andrade (2003) reportou que esse gênero possibilitou $\mathrm{o}$ aumento do rebanho nacional e a melhoria dos índices zootécnicos. Extensas áreas de pastagens foram implantadas em regiões marginais, de baixa produtividade agrícola, com forrageiras especialmente persistentes às condições adversas, em sistemas de produção extensivos (Cezar et al. 2005). Nesses sistemas de produção, a escolha correta da forrageira é especialmente relevante. Conhecer o efeito das condições ambientais nas plantas é importante na tomada de decisão, pois associar essa informação ao diagnóstico local possibilita conferir sustentabilidade ao sistema (Cândido et al., 2005).

O déficit hídrico interfere nas relações fisiológicas e anatômicas das plantas limitando o crescimento, o desenvolvimento e até mesmo a sobrevivência, sendo os efeitos dependentes da espécie de planta e da duração da deficiência hídrica (Duarte, 2012). Já o excesso de água no solo interfere, na maioria dos casos, no desenvolvimento de raízes e, indiretamente, na parte aérea, ocasionando murchamento, diminuição da capacidade fotossintética, concentração de nutrientes nas folhas e diminuição no crescimento (Visser et al., 2003).

A utilização da morfogênese como processo de estudo por busca de forrageiras que apresentem características de produção, adaptabilidade ao meio e tolerância hídrica possibilita definir estratégias de manejo que visa à melhoria na utilização da pastagem (Rodrigues, 2008; Pena et al., 2009). Dessa forma, objetivou-se avaliar as características estruturais e morfogênicas de algumas espécies e cultivares de Urochloa spp. sob diferentes condições hídricas no solo.

\section{MATERIAL E MÉTODOS}

O experimento foi conduzido no setor de ambientes protegidos da Universidade Estadual de Mato Grosso do Sul (UEMS), em
Aquidauana, MS, cujas coordenadas geográficas são: latitude $20^{\circ} 28^{\prime \prime} \mathrm{S}$ e longitude $55^{\circ} 48^{\prime \prime} \mathrm{W}$ e altitude de 207 metros. Foram avaliadas as forrageiras $U$. humidicola cv. Tully, $U$. humidicola cv. Llanero, $U$. decumbens cv. Basilisk, U. ruziziensis cv. Kenedy, U. brizantha cv. BRS Piatã e $U$. brizantha cv. Xaraés, em experimentos simultâneos, individualizados por espécie forrageira, realizados em vasos. Em cada experimento, testaram-se cinco tratamentos: $50 \%$ da capacidade de retenção de umidade pelo solo (CRU), 80\% da CRU, solo com 0cm de lâmina d'água, com lâmina d'água de $1 \mathrm{~cm}$ e com lâmina d'água de $5 \mathrm{~cm}$, arranjados em delineamento inteiramente ao acaso, com quatro repetições, com 20 unidades experimentais por forrageira, totalizando 120 unidades experimentais.

O solo utilizado para preenchimento dos vasos foi coletado na Fazenda da UEMS, localizado em área de reserva ambiental no setor de bovinocultura de corte, de Aquidauana, MS, na camada de $0-20 \mathrm{~cm}$ de profundidade. Da amostra inicial do solo, foi retirada uma subamostra para análise química do solo e, de acordo com os resultados, não houve necessidade de correção da acidez e de adubação do solo (Tab. 1).

Após, o solo foi peneirado em peneira de malha de quatro milímetros, e os vasos preenchidos com quantidade de solo correspondente ao volume de $7 \mathrm{dm}^{3}$ cada. Posteriormente, estes foram mantidos por 30 dias em fase de estabilização das condições físico-químicas, bem como conservados umedecidos a $80 \%$ da CRU do solo. Após o término desse período, realizouse a semeadura de cada espécie forrageira nos vasos e, uma semana após a emergência das plântulas, realizou-se o desbaste, deixando-se quatro plantas mais semelhantes. Depois de uma semana, foi realizado o corte de uniformização a $10 \mathrm{~cm}$ de altura da superfície do solo. Nos vasos que receberam o tratamento de lâmina d'água a 1 ou $5 \mathrm{~cm}$ da superfície do solo, foram colocadas estacas demarcadoras da altura de lâmina. Os vasos submetidos aos tratamentos de 50 e $80 \%$ da capacidade de retenção de umidade do solo tiveram suas condições monitoradas por meio de duas pesagens semanais.

Uma semana após o corte de uniformização, foram marcados quatro perfilhos em duas plantas diferentes, em cada espécie forrageira, para mensuração e determinação das características 
estruturais e morfogênicas. Foram medidos com régua: altura do pseudocolmo (altura da planta do solo até a lígula da última folha expandida) e comprimento de cada lâmina foliar, além do registro de ocorrências, como expansão da lâmina foliar, corte, morte das folhas e datas das mensurações.

Com base nos dados coletados, foram determinados:

taxa de aparecimento foliar (folha perfilho ${ }^{-1} \mathrm{dia}^{-}$ ${ }^{1}$ ): quociente entre o número de folhas por perfilho surgidas no período avaliado e o número de dias do período;

filocrono (dias): inverso da taxa de aparecimento de folhas (dias folha ${ }^{-1}$ perfilho $^{-1}$ );

taxa de alongamento foliar ( $\mathrm{cm}$ perfilho $\left.{ }^{-1} \mathrm{dia}^{-1}\right)$ : variação média no comprimento da folha em expansão durante o período de avaliação;

número de folhas vivas: contagem do número de folhas vivas, não senescentes;

duração de vida das folhas (dias); e

taxa de alongamento de colmo (cm perfilho $^{-1}$ $\left.\operatorname{dia}^{-1}\right)$ : variação média no comprimento do pseudocolmo/colmo durante o período de avaliação.

As variáveis foram avaliadas segundo um delineamento inteiramente ao acaso. Os efeitos de deficiência hídrica $(50 \%$ da capacidade de retenção de umidade), excesso hídrico ( $80 \%$ da capacidade de retenção de umidade), linear e quadrático em níveis de lâmina d’água (com lâmina d'água de $0 \mathrm{~cm}$, com lâmina d'água de $1 \mathrm{~cm}$ e com lâmina d'água de $5 \mathrm{~cm}$ ) foram avaliados pelo teste de $\mathrm{t}$ de student, quando cabível. Em todas as análises, adotou-se $\alpha=0,05$. As análises estatísticas foram realizadas com o uso do programa computacional SAS, v.9.2 (SAS Institute Inc., Cary, CA).

\section{RESULTADOS E DISCUSSÃO}

Os níveis de lâmina d'água, na cultivar Llanero, apresentaram efeito $(\mathrm{P}<0,05)$ quadrático na $\mathrm{TAlF}$ e linear sobre o NFV (Tab. 2).

$\mathrm{Na} U$. humidicola cv. Tully, não se observou efeito significativo em nenhuma de suas características (Tab. 2). Isso está relacionado com a capacidade de adaptação da $U$. humidicola cv. Tully ao alagamento, a qual paralisa o seu desenvolvimento e crescimento, como estratégia para permanecer viva (Soares Filho, 1994; Silva et al., 2007; Valle et al., 2010). A água é extremamente importante para o alongamento foliar da $U$. humidicola. No capim-llanero, porém, quando este foi submetido a um alagamento mais severo, observou-se redução na TAlF a partir de $1 \mathrm{~cm}$ de lâmina d'água (Tab. 2). Segundo Mattos et al. (2005), o aumento da disponibilidade de água no solo acarreta danos à planta, como diminuição da produção de oxigênio, redução das taxas de fotossíntese e de crescimento, resultando em queda da produção da parte aérea. $\mathrm{O}$ alongamento da folha é um dos processos fisiológicos mais sensíveis à umidade do solo, pois a planta cessa o crescimento de folhas e raízes muito antes dos processos de fotossíntese e divisão celular (Hsiao, 1973).

O alagamento do solo é capaz de diminuir a capacidade fotossintética em plantas sob esse estresse. Quando o capim-llanero foi submetido ao aumento da lâmina d'água, ocorreu uma redução na abertura estomática, ocasionando queda na capacidade fotossintética da forrageira (Dias Filho e Carvalho, 2000). A Urochloa humidicola cv. Llanero apresentou relação negativa entre o NFV e os níveis de alagamento. Em plantas forrageiras, segundo Rodrigues (2008), o volume de água no solo pode limitar a taxa de alongamento foliar, o número de folhas vivas e o número de perfilho. No presente trabalho, ocorreu uma redução no número de folhas vivas, o que demonstra menor tolerância ao excesso hídrico (Tab. 2). 
Tabela 1. Resultados de análise de solo (Iagro, 2011)

\begin{tabular}{|c|c|c|c|c|c|c|c|c|c|c|c|}
\hline Amostra & $\mathrm{pH}$ & $\begin{array}{c}P \\
\mathrm{ug} / \mathrm{cm}^{3}\end{array}$ & M.O. \% & Textura & \multicolumn{7}{|c|}{$\mathrm{Emg} / 100 \mathrm{~cm}^{3}$} \\
\hline \multirow[t]{6}{*}{01} & 5,6 & 13,3 & 1,4 & 2 & $\begin{array}{c}0,3 \\
1\end{array}$ & 1,2 & 0,6 & 0,2 & 2,4 & 2 , & 4,51 \\
\hline & \multicolumn{3}{|c|}{ Relações } & \multicolumn{8}{|c|}{ Saturações ( \% ) } \\
\hline & \multirow{2}{*}{\multicolumn{2}{|c|}{$\begin{array}{l}\mathrm{Ca} / \mathrm{Mg} \\
2,0\end{array}$}} & $\mathrm{Ca}+\mathrm{Mg} / \mathrm{k}$ & $\mathrm{Ca}$ & \multirow{2}{*}{\multicolumn{2}{|c|}{$\begin{array}{l}\mathrm{Mg} \\
13,3\end{array}$}} & $\mathrm{~K}$ & & 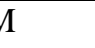 & $\mathrm{H}$ & $\mathrm{V}$ \\
\hline & & & 5,8 & 26,6 & & & 6,9 & &, 7 & 48,8 & 46,78 \\
\hline & \multicolumn{2}{|c|}{ Argila (\%) } & $\begin{array}{l}\text { Silte ou } \\
\text { limo }(\%)\end{array}$ & $\begin{array}{c}\text { Areia } \\
\text { total }(\%)\end{array}$ & \multicolumn{3}{|c|}{$(\%)$} & \multicolumn{2}{|c|}{$\begin{array}{c}\text { Areia } \\
\text { média }(\%)\end{array}$} & \multicolumn{2}{|c|}{$\begin{array}{c}\text { Areia } \\
\text { grossa }(\%)\end{array}$} \\
\hline & \multicolumn{2}{|c|}{16} & 27 & 57 & \multicolumn{3}{|c|}{-} & \multicolumn{2}{|c|}{-} & \multicolumn{2}{|r|}{-} \\
\hline
\end{tabular}

Tabela 2. Caracterização estrutural e morfogênica de forrageiras da Urochloa humidicola cv. Tully e Llanero, sob diferentes condições hídricas no solo

\begin{tabular}{|c|c|c|c|c|c|c|c|c|c|c|}
\hline \multirow[t]{2}{*}{ Variável $^{1}$} & \multicolumn{5}{|c|}{ Níveis de condição hídrica } & \multirow{2}{*}{$\begin{array}{l}\text { CV } \\
(\%)\end{array}$} & \multicolumn{2}{|c|}{$\begin{array}{c}\text { Efeito de } \\
\text { condição geral }\end{array}$} & \multicolumn{2}{|c|}{$\begin{array}{c}\text { Nível de lâmina } \\
\text { d'água }\end{array}$} \\
\hline & $50 \%$ & $80 \%$ & $0 \mathrm{~cm}$ & $1 \mathrm{~cm}$ & $5 \mathrm{~cm}$ & & Déficit & $\begin{array}{c}\text { Excess } \\
0\end{array}$ & Linear & $\begin{array}{c}\text { Quadráti } \\
\text { co }\end{array}$ \\
\hline \multicolumn{11}{|c|}{ Urochloa humidicola cv. Tully } \\
\hline TApF & 0,11 & 0,10 & 0,10 & 0,12 & 0,11 & 46,5 & 0,90 & 0,84 & 0,94 & 0,53 \\
\hline Filocrono & 9,71 & 8,94 & 9,41 & 9,85 & 11,81 & 52,8 & 0,84 & 0,65 & 0,50 & 0,99 \\
\hline TAlF & 2,81 & 3,09 & 2,78 & 3,28 & 2,25 & 47,3 & 0,77 & 0,69 & 0,42 & 0,49 \\
\hline TAlC & 0,38 & 0,51 & 0,35 & 0,57 & 0,38 & 44,8 & 0,35 & 0,39 & 0,44 & 0,09 \\
\hline NFV & 4,13 & 2,88 & 3,50 & 4,38 & 3,50 & 29,4 & 0,12 & 0,16 & 0,67 & 0,23 \\
\hline DVF & 37,18 & 26,69 & 30,63 & 40,90 & 36,10 & 35,4 & 0,24 & 0,21 & 0,79 & 0,26 \\
\hline \multicolumn{11}{|c|}{ Urochloa humidicola cv. Llanero } \\
\hline TApF & 0,04 & 0,04 & 0,06 & 0,04 & 0,05 & 57,0 & 0,90 & 0,67 & 0,73 & 0,32 \\
\hline Filocrono & 17,5 & 10,5 & 15,31 & 14,44 & 17,06 & 42,6 & 0,17 & 0,18 & 0,61 & 0,77 \\
\hline TAlF & 4,30 & 3,53 & 2,37 & 4,28 & 2,69 & 32,7 & 0,35 & 0,54 & 0,66 & 0,02 \\
\hline TAlC & 0,39 & 0,41 & 0,36 & 0,26 & 0,23 & 42,2 & 0,80 & 0,14 & 0,27 & 0,44 \\
\hline NFV & 2,50 & 2,50 & 3,25 & 2,31 & 1,50 & 26,8 & 0,11 & 0,72 & 0,01 & 0,24 \\
\hline DVF & 49,0 & 27,56 & 55,56 & 28,0 & 28,88 & 47,5 & 0,14 & 0,36 & 0,15 & 0,12 \\
\hline
\end{tabular}

${ }^{1}$ TApF: taxa de aparecimento de folhas (folha.perfilho ${ }^{-1}$ dia $^{-1}$ ); filocrono: inverso da TApF (dias folha ${ }^{-1}$ perfilho $\left.{ }^{-1}\right)$; TAlF: taxa de alongamento foliar $\left(\mathrm{cm}_{\text {perfilho }}{ }^{-1} \mathrm{dia}^{-1}\right)$; TAlC: taxa de alongamento de colmo (cm perfilho ${ }^{-1}$ dia $^{-1}$ ); NFV: número de folhas vivas; DVF: duração de vida das folhas (dias).

Fagundes et al. (2006) observaram que as mudanças na estrutura e composição morfológicas da pastagem, decorrentes do número de folhas verdes por perfilho, determinaram a quantidade máxima de tecido foliar verde acumulada no perfilho e associado ao número de perfilhos por área, contribui para o índice de área foliar. Assim, explica-se o menor desenvolvimento do capim-llanero, quando submetido ao alagamento. Os resultados com Urochloa brizantha (cv. Piatã e cv. Xaraés) estão apresentados na Tab. 3. 
Tabela 3. Caracterização estrutural e morfogênica de cultivares da espécie Urochloa brizantha sob diferentes condições hídricas no solo

\begin{tabular}{|c|c|c|c|c|c|c|c|c|c|c|}
\hline \multirow[t]{2}{*}{ Variável } & \multicolumn{5}{|c|}{ Níveis de condição hídrica } & \multirow{2}{*}{$\begin{array}{l}\mathrm{CV} \\
(\%)\end{array}$} & \multicolumn{2}{|c|}{$\begin{array}{l}\text { Efeito de condição } \\
\text { geral }\end{array}$} & \multicolumn{2}{|c|}{$\begin{array}{l}\text { Nível de lâmina } \\
\text { d'água }\end{array}$} \\
\hline & $50 \%$ & $80 \%$ & $0 \mathrm{~cm}$ & $1 \mathrm{~cm}$ & $5 \mathrm{~cm}$ & & Déficit & $\begin{array}{c}\text { Excess } \\
0\end{array}$ & Linear & $\begin{array}{l}\text { Quadrá } \\
\text { tico }\end{array}$ \\
\hline \multicolumn{11}{|c|}{ Urochloa brizantha cv. BRS Piatã } \\
\hline TApF & 0,13 & 0,11 & 0,15 & 0,11 & 0,10 & 29,23 & 0,32 & 0,51 & 0,12 & 0,24 \\
\hline Filocrono & 9,27 & 11,52 & 8,08 & 11,27 & 12,25 & 35,26 & 0,40 & 0,65 & 0,11 & 0,34 \\
\hline TAlF & 6,87 & 5,38 & 5,11 & 5,47 & 4,21 & 15,11 & 0,02 & 0,36 & 0,06 & 0,32 \\
\hline TAlC & 0,50 & 0,48 & 0,36 & 0,32 & 0,56 & 34,25 & 0,84 & 0,45 & 0,04 & 0,42 \\
\hline NFV & 2,92 & 2,46 & 2,69 & 2,50 & 2,67 & 21,50 & 0,27 & 0,63 & 0,91 & 0,63 \\
\hline DVF & 26,97 & 26,62 & 21,85 & 29,21 & 32,89 & 31,82 & 0,96 & 0,79 & 0,14 & 0,38 \\
\hline \multicolumn{11}{|c|}{ Urochloa brizantha cv. Xaraés } \\
\hline TApF & 0,09 & 0,09 & 0,10 & 0,11 & 0,08 & 22,4 & 0,86 & 0,63 & 0,17 & 0,34 \\
\hline Filocrono & 13,6 & 13,1 & 12,7 & 11,5 & 14,7 & 19,7 & 0,81 & 0,90 & 0,16 & 0,35 \\
\hline TAlF & 5,40 & 6,19 & 5,84 & 5,52 & 4,67 & 21,6 & 0,36 & 0,24 & 0,17 & 0,91 \\
\hline TAlC & 0,20 & 0,15 & 0,25 & 0,45 & 0,23 & 79,6 & 0,75 & 0,21 & 0,51 & 0,15 \\
\hline NFV & 2,63 & 2,38 & 2,44 & 2,32 & 2,67 & 22,7 & 0,54 & 0,77 & 0,45 & 0,65 \\
\hline DVF & 32,5 & 31,3 & 27,3 & 26,3 & 37,8 & 37,1 & 0,88 & 0,91 & 0,15 & 0,67 \\
\hline
\end{tabular}

${ }^{1}$ TApF: taxa de aparecimento de folhas (folha.perfilho ${ }^{-1}$ dia $^{-1}$ ); filocrono: inverso da TApF (dias folha ${ }^{-1}$ perfilho ${ }^{-1}$ ); TAlF: taxa de alongamento foliar (cm perfilho- $\mathrm{dia}^{-1}$ ); TAlC: taxa de alongamento de colmo (cm perfilho ${ }^{-1}$ dia $^{-1}$ ); NFV: número de folhas vivas; DVF: duração de vida das folhas (dias).

Observou-se efeito $(\mathrm{P}<0,05)$ do déficit hídrico sobre a TAlF e efeito linear para nível de lâmina d'água sobre a TAlC do capim-piatã (Tab. 3). A Urochloa brizantha cv. BRS Piatã respondeu de forma positiva ao déficit hídrico, alongando suas folhas para otimizar sua área fotossintetizante, com o intuito de melhorar sua capacidade de responder ao estresse. $\mathrm{O}$ alongamento do colmo em maiores lâminas d'água é resultado desse ambiente a que a planta está submetida e do aumento da distância entre parte aérea e lâmina d'água, permitindo, assim, captar maior quantidade de luz (Sbrissia e Silva, 2001).

Segundo Caetano (2006), a taxa de alongamento foliar é um indicador visual do crescimento e desenvolvimento da planta e se mostra sensível ao estresse hídrico, bem como varia entre espécies de um mesmo gênero. Dias Filho (2005) relatou que as plantas modificam suas funções fisiológicas (taxa de crescimento, taxa fotossintética, renovação foliar etc.) para manter suas atividades vitais. O capim-piatã parece ter realizado modificações anatômicas nas folhas e nos colmos, que contribuíram para sua sobrevivência, principalmente nas condições de estresse por alagamento.

No capim-xaraés não se observou efeito $(\mathrm{P}<0,05)$ das diferentes condições hídricas para nenhuma das características avaliadas. Quintino et al. (2010), ao avaliarem três cultivares de Urochloa brizantha (Marandu, Xaraés e Piatã), verificaram que o capim-xaraés não apresentou diferença no índice área foliar quando cultivado sob alagamento. Dias Filho e Queiroz (2003), ao compararem a tolerância ao alagamento de cultivares de $U$. brizantha, observaram que ocorreu uma redução na taxa de fotossíntese do capim-xaraés quando submetido ao alagamento.

Os resultados para as cultivares de Urochloa decumbens $\mathrm{cv}$. Basilisk e ruziziensis cv. Kenedy estão apresentados na Tab. 4. Para o capimruziziensis, observou-se efeito $(\mathrm{P}<0,05)$ da deficiência hídrica, efeito linear e quadrático de lâmina d'água para TApF. Observou-se efeito $(\mathrm{P}<0,05)$ da deficiência e do excesso hídrico, efeito linear da lâmina d'água sobre o filocrono e efeito de deficiência hídrica sobre a DVF. 
Tabela 4. Caracterização estrutural e morfogênica de Urochloa decumbens cv. Basilisk e U. ruziziensis cv. Kenedy sob diferentes condições hídricas no solo

\begin{tabular}{|c|c|c|c|c|c|c|c|c|c|c|}
\hline \multirow[t]{2}{*}{ Variável } & \multicolumn{5}{|c|}{ Níveis de condição hídrica } & \multirow{2}{*}{$\begin{array}{l}\mathrm{CV} \\
(\%)\end{array}$} & \multicolumn{2}{|c|}{$\begin{array}{l}\text { Efeito de condição } \\
\text { geral }\end{array}$} & \multicolumn{2}{|c|}{$\begin{array}{l}\text { Nível de lâmina } \\
\text { d'água }\end{array}$} \\
\hline & $50 \%$ & $80 \%$ & $0 \mathrm{~cm}$ & $1 \mathrm{~cm}$ & $5 \mathrm{~cm}$ & & Déficit & Excesso & Linear & Quadrático \\
\hline \multicolumn{11}{|c|}{ Urochloa decumbens cv. Basilisk } \\
\hline TApF & 0,12 & 0,11 & 0,10 & 0,13 & 0,12 & 16,3 & 0,36 & 0,33 & 0,22 & 0,06 \\
\hline Filocrono & 11,2 & 10,7 & 11,8 & 10,1 & 8,68 & 21,7 & 0,80 & 0,68 & 0,09 & 0,46 \\
\hline TAIF & 3,57 & 3,91 & 3,21 & 3,21 & 4,15 & 31,6 & 0,68 & 0,56 & 0,20 & 0,80 \\
\hline TAlC & 0,42 & 0,51 & 0,52 & 0,52 & 0,65 & 24,7 & 0,34 & 0,48 & 0,14 & 0,81 \\
\hline NFV & 4,02 & 3,98 & 3,70 & 3,78 & 3,40 & 11,3 & 0,87 & 0,18 & 0,24 & 0,63 \\
\hline DVF & 44,0 & 42,0 & 43,5 & 34,5 & 29,7 & 19,7 & 0,72 & 0,18 & 0,04 & 0,22 \\
\hline \multicolumn{11}{|c|}{ Urochloa ruziziensis cv. Kenedy } \\
\hline TApF & 0,11 & 0,16 & 0,13 & 0,17 & 0,11 & 19,88 & 0,01 & 0,12 & 0,03 & 0,03 \\
\hline Filocrono & 12,14 & 6,68 & 8,76 & 8,02 & 11,96 & 20,47 & 0,01 & 0,02 & 0,01 & 0,29 \\
\hline TAlF & 4,51 & 4,51 & 5,96 & 5,27 & 5,12 & 31,76 & 0,11 & 0,33 & 0,55 & 0,62 \\
\hline TAlC & 0,53 & 0,29 & 0,40 & 0,56 & 0,45 & 43,83 & 0,11 & 0,14 & 0,13 & 0,26 \\
\hline NFV & 3,63 & 3,54 & 3,48 & 3,25 & 3,10 & 21,19 & 0,87 & 0,54 & 0,52 & 0,75 \\
\hline DVF & 44,74 & 21,31 & 30,50 & 22,57 & 37,70 & 34,22 & 0,01 & 0,17 & 0,16 & 0,20 \\
\hline
\end{tabular}

${ }^{1}$ TApF: taxa de aparecimento de folhas (folha perfilho ${ }^{-1}$ dia $^{-1}$ ); filocrono: inverso da TApF (dias folha ${ }^{-1}$ perfilho ${ }^{-1}$ ); TAlF: taxa de alongamento foliar $\left(\mathrm{cm}\right.$ perfilho ${ }^{-1} \mathrm{dia}^{-1}$ ); TAlC: taxa de alongamento de colmo (cm perfilho ${ }^{-1}$ dia $^{-1}$ ); NFV: número de folhas vivas; DVF: duração de vida das folhas (dias).

O aumento na TApF com os níveis de lâmina d'água deve-se à importância da água no metabolismo da planta. No entanto, a queda no seu desenvolvimento pode estar associada a um desbalanço hormonal e à diminuição da capacidade de extensão da parede celular (Armstrong et al., 1994; Zhang e Davies, 1986). $\mathrm{O}$ alagamento proporcionou redução do filocrono à medida que se aumentou o nível de lâmina d'água, bem como reduziu o intervalo de tempo necessário para o surgimento de duas folhas consecutivas em busca de maior capacidade fotossintética.

A DVF é influenciada pelo ambiente, pelo desenvolvimento da planta e pelas características da própria forrageira. $\mathrm{O}$ aumento na duração de vidas das folhas consiste no equilíbrio desses fatores com a resistência delas as condições de estresse hídrico (Nabinger, 1997). Ocorreu diminuição na DVF à medida que se aumentou a lâmina d'água. Durante $\mathrm{o}$ processo de alagamento, a planta precisou utilizar respostas adaptativas devido às condições impostas pelo ambiente, sendo a DVF uma das características afetadas pelo alagamento (Nabinger, 1997). Assim, a planta não manteve seu ritmo de desenvolvimento e de renovação do material foliar verde nessas condições ambientais.
O mesmo fato aconteceu quando essa forrageira estava sob alagamento, pois as características foram inversamente proporcionais, indicando que o aumento do nível de lâmina d'água no solo tornou cada vez mais difícil o processo de crescimento e a renovação dos tecidos da planta. Isso demonstra a falta de capacidade dessa gramínea em se adaptar às condições de alagamento, uma vez que os parâmetros fisiológicos não se equilibraram em um determinado nível.

No capim-braquiária não se observou efeito $(\mathrm{P}<0,05)$ das diferentes condições hídricas do solo para nenhuma das características avaliadas (Tab. 4). Alves et al. (2008), quando submeteram Urochloa decumbens cv. Basilisk a diferentes doses de nitrogênio e volumes de água observaram que a água é fundamental no metabolismo da planta. Assim, em condições hídricas ideais, o capim-braquiária renovou suas folhas mais rapidamente, em razão do melhor aproveitamento dos recursos disponíveis. A queda no desenvolvimento da planta pode estar associada a um desbalanço hormonal e à diminuição da capacidade de extensão da parede celular (Armstrong et al., 1994; Zhang e Davies, 1986). 


\section{CONCLUSÃO}

A Urochloa humidicola cv. Tully mostrou-se tolerante às diversas condições hídricas, ou seja, tanto à deficiência hídrica como ao alagamento. Entretanto, o alagamento comprometeu o desenvolvimento da $U$. humidicola cv. Llanero, porém a $U$. brizantha $\mathrm{cv}$. Piatã suportou o déficit hídrico e adaptou-se ao alagamento. Já $U$. decumbens apresentou tolerância ao excesso de água no solo. A $U$. ruziziensis desenvolveu mecanismo de adaptação para persistir nas condições de déficit hídrico e teve seu desenvolvimento retardado quando submetida ao alagamento.

\section{REFERÊNCIAS}

ALVES, J.S.; PIRES, A.J.V.; MATSUMOTO, M.P.; RIBEIRO, G.S. Características morfológicas e estruturais da Brachiaria decumbens Stapf. submetida a diferentes doses de nitrogênio e volumes de água. Acta. Vet. Bras., v.2, p.1-10, 2008.

ANDRADE, F.M.E. de. Produção de forragem e valor alimentício de capim-marandu submetido a regimes de lotação contínua por bovinos de corte. 2003. 125f. Dissertação (Mestrado em Agronomia) - Universidade de São Paulo, Piracicaba, SP.

ARMSTRONG, W.; BRÂNDLE, R.; JACKSON, M.B. Mechanismos of fllod tolerance in plants. Acta Botanica Neerlandica. v.43, p.307-358, 1994.

CAETANO, L.P.S. Tolerância de seis acessos de Brachiaria spp. ao alagamento. 2006. 63f. Dissertação (Mestrado em Botânica Tropical) Universidade Federal Rural da Amazônia, Belém, AM.

CÂNDIDO, M.J.D.; GOMIDE， C.A.M.; ALEXANDRINO, E. et al. Morfofisiológica do dossel de Panicum maximum cv. Mombaça sob lotação intermitente com três períodos de descanso. Rev. Bras. Zootec., v.34, p.406-415, 2005 .

CEZAR, I.M.C.; QUEIROZ, H.P.; THIAGO, L.R.L.S. et al. Sistemas de produção de gado de corte no Brasil: uma descrição com ênfase no regime alimentar e no abate. Campo Grande, MS: Embrapa - CNPGC, 2005. 40p. (Documentos 151).
DIAS FILHO, M.B. Opções forrageiras para aéreas sujeitas à inundação ou alagamento temporário. In: PEDREIRA, C.G.S.; MOURA, J.C.; SILVA, S.C.; FARIA, V.P. (Eds.). Simpósio sobre manejo de pastagem. teoria e prática da produção animal em pastagens, 22., 2005, Piracicaba. Anais... Piracicaba: FEALQ, 2005. p.71-93.

DIAS FILHO, M.B.; QUEIROZ, R.J.B. Tolerância ao alagamento do solo em seis acessos de Brachiaria brizantha. In: Reunião Anual Da Sociedade Brasileira De Zootecnia, 40., 2003, Santa Maria. Anais... Santa Maria: SBZ, 2003. p.1-4.

DIAS FILHO, M.B.; CARVALHO, C.J.R. Physiological and morphological responses of Brachiaria spp. to flooding. Pesqui. Agropecu. Bras., v.35, p.1959-1966, 2000.

DUARTE, A.L.M. Efeito da água sobre o crescimento e o valor nutritivo das plantas forrageiras. Pesqui. Tecnol., v.9, p.1-6, 2012.

FAGUNDES, J.L.; FONSECA, D.M.; MISTURA, C. et al. Características morfogênicas e estruturais do capim-braquiária em pastagem adubada com nitrogênio avaliadas nas quatro estações do ano. Rev. Bras. Zootec., v.35, p.22-29, 2006.

HSIAO, T.C. Plant response to water stress. Ann. Rev. Plant Physiol., v.24, p.519-570, 1973.

MATTOS, J.L.S.; GOMIDE, J.A.; HUAMAN, C.A.M. Crescimento de espécies do gênero Brachiaria, sob déficit hídrico, em casa de vegetação. Rev. Bras. Zootec., v.34, p.765-773, 2005.

NABINGER, C. Eficiência do uso de pastagens: disponibilidade e perdas de forragem. In: Simpósio sobre manejo da pastagem, 14., 1997, Piracicaba. Anais... Piracicaba: [FEALQ], 1997. p.231-251.

PENA, K.S.; NASCIMENTO JR. D.; SILVA, S.C. et al. Características morfogênicas, estruturais e acúmulo de forragem do capimtanzânia submetido a duas alturas e três intervalos de corte. Rev. Bras. Zootec., v.38, p.2127-2136, 2009. 
QUINTINO, A.C.; BONFIM SILVA, E.M.; STIEVEN, A.C. et al. Características produtivas de braquiárias submetidas a duas disponibilidades hídricas. Enci. Bio., v.6, p.1-8, 2010.

RODRIGUES, C.S. Caracterização morfogênica de gramíneas forrageiras tropicais sob crescimento livre. 2008. 87f. Dissertação (Mestrado em Zootecnia) - Universidade Federal de Viçosa, Viçosa, MG.

SBRISSIA, A.F.; SILVA, S.C. O ecossistema de pastagens e a produção animal In: Reunião anual da socidade brasileira de zootecnia, 38., 2001, Piracicaba. Anais... Piracicaba: SBZ, 2001. p.731-754.

SILVA, A.S. et al. Biomassa seca da raiz e da parte aérea de cultivares de Brachiaria brizantha e de B. humidicola alagadas e não alagadas. Rev. Bras. Biociênc., v.5, p.123-125, 2007.

SOARES FILHO, C.V. Recomendações de espécies e variedades de Brachiaria para diferentes condições. In: Simpósio sobre manejo da pastagem, 11., 1994, Piracicaba. Anais... Piracicaba: Escola Superior de Agricultura Luiz de Queiroz, 1994.
VALLE, C.B.; EUCLIDES, V.P.B.; MACEDO, M.C. Características de plantas forrageiras do gênero Brachiaria. In: Simposio sobre o manejo da pastagem, 17., Piracicaba, 2001. Anais... Piracicaba: FEALQ, 2001. p.133-176.

VALLE, C.B.; EUCLIDES, V.P.B.; PEREORA, J.M. et al. O capim-xaraés (Brachiaria brizantha cv. Xaraés) na diversificação das pastagens de braquiária. Campo Grande, MS: Embrapa Gado de Corte, 2004. 36p. (Documentos 149).

VALLE, C.B.; MACEDO, M.C.M.; EUCLIDES, V.P.B. et al. Gênero Brachiaria. In: FONSECA, D.M. MARTUSCELLO, J.A. (Eds.). Plantas forrageiras. Viçosa: UFV, 2010. p.30-77.

VISSER， E.J.W.; VOESENEK， L.A.C.J.; VARTAPETIAN, B.B.; JACKSON, M.B. Flooding and plant growth. Ann. Bot., v.91, p.107-109, 2003.

ZHANG J.; DAVIES W. J. Chemical and hydraulic influences on the stomata iof flooded plant. J. Exp. Bot., v.37, p.1479-1491, 1986. 